\title{
Gold and nickel alkyl substituted bis-thiophenedithiolene complexes: anionic and neutral forms
}

\author{
Marta M. Andrade, ${ }^{[a]}$ Rafaela A. L. Silva, ${ }^{[a]}$ Isabel C. Santos, ${ }^{[a, b]}$ Elsa B. Lopes, ${ }^{[a]}$ Sandra Rabaça, ${ }^{[a]}$ \\ Laura C.J. Pereira, ${ }^{[a]}$ Joana T. Coutinho, ${ }^{[\mathrm{a}]}$ João P. Telo ${ }^{[\mathrm{b}]}$ Concepció Rovira, ${ }^{[\mathrm{c}]}$ Manuel Almeida ${ }^{[\mathrm{a}]}$ and \\ Dulce Belo ${ }^{[a]}$
}

\begin{abstract}
The Au and Ni monoanionic complexes of ter-buthyl and diisopropyl substituted thiophedithiolate ligand $\left[\mathrm{M}(\alpha-\mathrm{tb}-\mathrm{tpdt})_{2}\right]$ and $\left[\mathrm{M}(\alpha-\mathrm{dp}-\mathrm{tpdt})_{2}\right]$, were synthesized and characterized namely by single crystal X-Ray diffraction and magnetic susceptibility measurements. These complexes, prepared in a first step as monoanioc species, are easier to oxidized than the related nonsubstituted thiophenedithiolates and could be obtained also as stable neutral species, As expected, the peripheral alkyl groups in the ligands confer also to the complexes an high solubility in common organic solvents, The neutral gold complex [Au( $\alpha$-tbtpdt $\left.)_{2}\right]$ presents a significant ligand asymmetry indicative of unpaired electron localization in one ligand at variance with $\left[\mathrm{Au}(\alpha-\mathrm{dp}-\mathrm{tpdt})_{2}\right]$ that is within experimental uncertainty fully symmetric illustrating the role of the intermolecular interactions in the stabilization of SOMO 'SOMO interactions. While in $\left[\mathrm{Au}(\alpha-\text { tbtpdt })_{2}\right]$ a significantr intermolecular interaction between paramagnetic molecules is possible leading to diamagnetic dimers of molecules, in [Au( $\alpha-\mathrm{dp}$ tpdt $)_{2}$ the bulkier substituents prevent the intermolecular interactions, leading to a regular stacking of molecules in symmetrical configuration. The regular stacks of paramagnetic [Au( $\left.\alpha-d p-t p d t)_{2}\right]$ units behave at high temperatures as an antiferromagnetic chains undergoing an AFM transition at ca. $25 \mathrm{~K}$.
\end{abstract}

\section{Introduction}

Transition metal bisdithiolene complexes have been a topic of intensive research during the last decades gaining increasing relevance in different fields such as materials science, analytical chemistry, catalysis and biological systems. The square planar coordination geometry of these complexes with extended piligands is quite favorable to establish strong face to face intermolecular interactions in the solid state. Due to significant ligand contribution to the frontier orbitals bisdithiolene complexes present a quite vivid redox behavior with diverse stable oxidation states, associated with different magnetic

[a] Dr. M.M. Andrade, R. A. L. Silva, Dr. I. C. Santos, Dr. E.B. Lopes, Dr. S. Rabaça, Dr. L.C.J. Pereira, J.T. Coutinho, Prof. M. Almeida, Dr. D. Belo

Department: $\mathrm{C}^{2} \mathrm{TN}$, Centro de Ciências e Tecnologias Nucleares, Institution: Instituto Superior Técnico, Universidade de Lisboa Address: E.N. 10 ao km 139,7, 2695-066 Bobadela LRS, Portugal 1

E-mail: dbelo@ctn.tecnico.ulisboa.pt

[b] Dr. I. C. Santos, Dr. J.P. Telo

Department: Centro de Química Estrutural,

Institution: Instituto Superior Técnico, Universidade de Lisboa

Address: Av. Rovisco Pais, P-1049-001 Lisboa, Portugal

[c] Prof. C. Rovira

Institution: Institut de Ciencia de Materials de Barcelona (ICMAB-

CSIC) and CIBER-BBN,

Address: Campus UAB, E-08193 Bellaterra, Spain moments, making them choice building blocks for the preparation of conducting and magnetic molecular materials. ${ }^{[1],[2]}$ The discovery that some of these complexes in the neutral state can present high electrical conductivity, ${ }^{[3][4][5]}$ realizing a new paradigm of molecular conductors, the so called single componente molecular metals (SCMM), has stimulated a special interest in bisdithiolene complexes which are stable in the neutral state. However the neutral complexes tend to present relatively low solubility severely limiting the possibility of many studies namely their isolation as single crystals. This was the case of $\left[\mathrm{Au}(\alpha-\mathrm{tpdt})_{2}\right](\alpha$-tpdt $=2,3$-thiophenedithiolate), the first highly conducting metallic compound based on a neutral species with a room-temperature conductivity $\left(\sigma_{R T}\right)$ of $7 \mathrm{~S} / \mathrm{cm}$ as a polycrystalline sample, which could never be obtained as single crystals. ${ }^{3}$ ] Other neutral complexes based on more extended ligands have been reported with high electrical conductivity ${ }^{[}{ }^{[6]}$ but due to their rather low solubility only some of them could be characterized in small single crystals as SCMM. ${ }^{[4]}$

An obvious way to increase the solubility of these complexes is the functionalization with appropriated substituents. However these substituents, particularly those more bulky can limit the solid state intermolecular interactions. This is the case of several alkyl thiazolil dithiolene complexes which due to increased solubility have been more easily obtained in the neutral state as single crystals and characterized as highly conducting materials in spite the restrains imposed by the substituents on the solid state interactions. ${ }^{[7][8][9]}$ Concerning the 2,3-thiophenedithiolate ligand the substitution with methyl groups has been already described leading to complexes with a limited gain in solubility, however with poor electrical conductivity of the neutral complex characterized as a polycrystalline sample. ${ }^{[10]}$

In this paper we report the preparation of ter-buthyl and diisopropyl substituted thiophedithiolate complexes [M( $\alpha-t b$ tpdt $\left.)_{2}\right], \quad\left[\mathrm{M}(\alpha-d p \text {-tpdt })_{2}\right], \quad \mathrm{M}=\mathrm{Au}$ and $\mathrm{Ni}, \quad(\alpha-t b$-tpdt= 5-(tertbutyl)thieno[2,3-d][1,3]dithiolate and $\alpha$ - $d p$-tpdt $=\quad 5,6$ diisopropylthieno[2,3-d][1,3]dithiolate) obtained in stable anionic and neutral forms as well as their structural, electric and magnetic properties.

\section{Results and Discussion}

\section{Synthesis}

The key compounds for the preparation of the complexes are ketones 5-(tert-butyl)thieno[2,3-d][1,3]dithiol-2-one (II) and 5,6diisopropylthieno[2,3-d][1,3]dithiol-2-one (III), as ligand 
precursors. Ketone II was prepared by a previously described Friedel-Craft alkylation of I. ${ }^{[11]}$ The ketone III was obtained by a similar procedure in a fair yeld of $60 \%$.

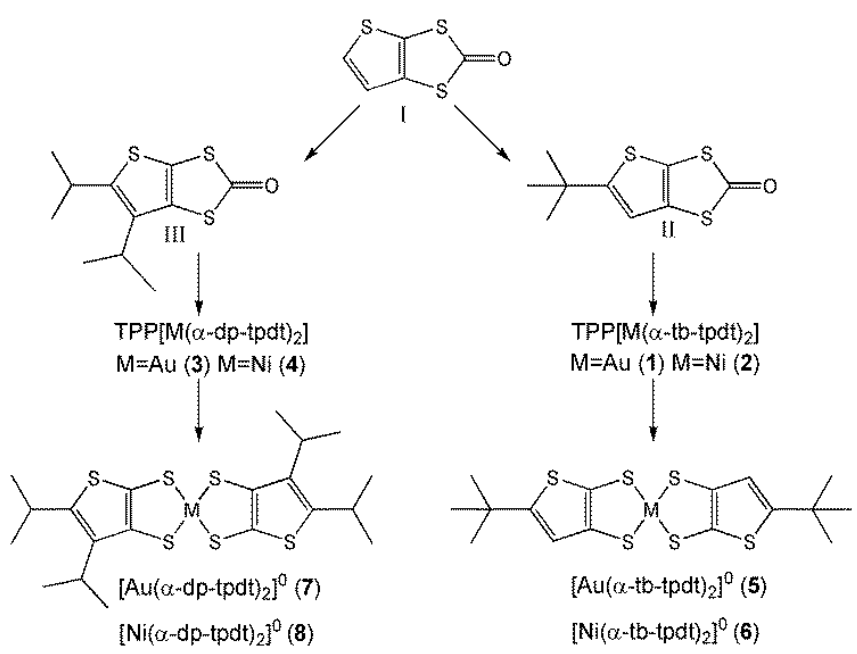

Scheme 1. Preparation route for alkyl substituted bis-thiophenedithiolene complexes 1-8.

The monoanionic gold ( $\mathbf{1}$ and $\mathbf{3}$ ) and nickel ( $\mathbf{2}$ and $\mathbf{4})$ complexes based on these alkyl substitute ligands, ( $\alpha$-tb-tpdt) and ( $\alpha$-dptpdt), where isolated as $\mathrm{Ph}_{4} \mathrm{P}^{+}$salts following a common procedure usually employed for the preparation of many diothiolene complexes, which is based on the hydrolytic cleavage of ketone II and III under strictly anaerobic conditions, with sodium methoxide in methanol (Scheme 1). The free dithiolate in solution reacts subsequently with the appropriate metal chloride and $\mathrm{Ph}_{4} \mathrm{PBr}$, to yield the salt of the monoanionic complex. The yields range from $30-43 \%$.

These salts of monoanionic complexes are fairly soluble and were easily obtained in a crystalline form by recrystallization in dichloromethane, from where crystals suitable for $x$-ray single crystal analysis could be easily isolated.

The neutral complexes 5-8 were obtained by oxidation of the monoanionic complexes with iodine and single crystals suitable for $x$-ray single crystal could be easily obtained by slow diffusion of iodine into a solution containing the monoanionic complex.

\section{Cyclic Voltammetry}

The redox properties of these gold and nickel complexes were studied by cyclic voltammetry. The voltammograms, obtained in dichloromethane under the same conditions, for compounds 1-4, present in all cases two pairs of waves corresponding to two quasi reversible processes as shown in Figure 1. From the comparison with related bisdithiolene complexes, these waves are ascribed in case of $\mathrm{Ni}$ complexes, to the dianionic/monoanionc and monoanionic/neutral couples, while in the case of the Au complexes to the monoanionic/neutral, and neutral/cationic couples. The corresponding redox potentials are compared in Table 1 to those of closely related complexes.
From this comparison it results that the alkyl substituted dithiothiophene metal complexes are, as expected, easier to oxidize, namely to the neutral species, than the unsubstituted analogues, and in case of gold even cationic species are expected to be stable.

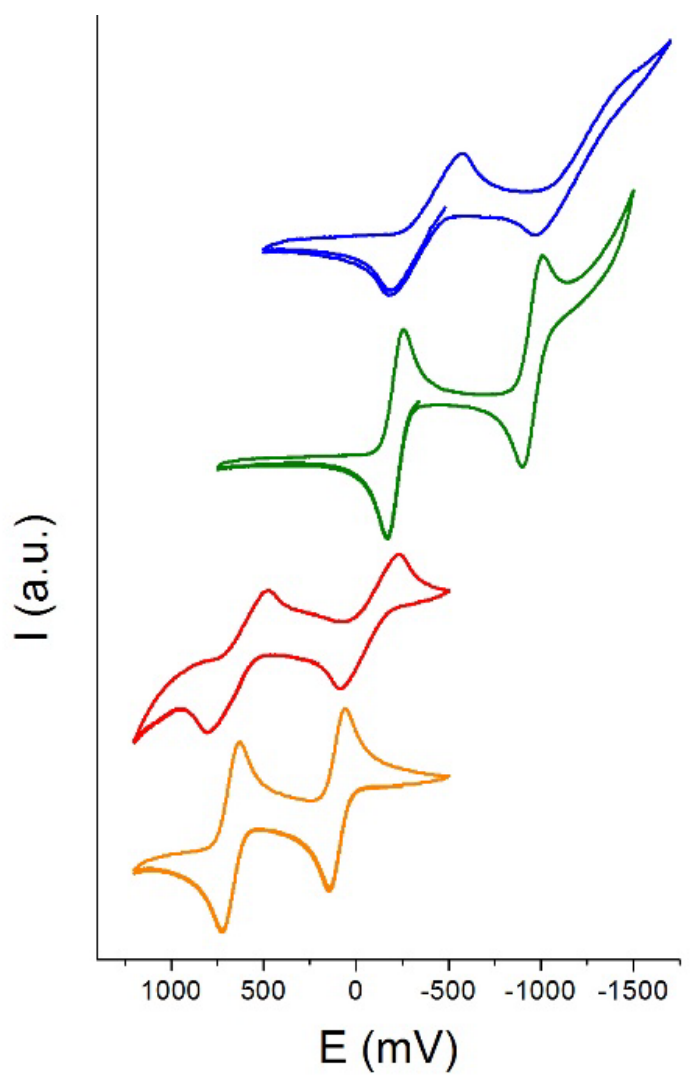

Figure 1. Cyclic voltammetry of 1 (orange), 2 ( green), 3 (red) and 4 (blue)

In view of these redox properties, and as confirmed experimentally, the neutral gold and nickel complexes with both ligands are expected to be stable and easily prepared by chemical or electrochemical oxidation of the monoanic complexes. However the large solubility of the neutral complex prevents the growth of crystals on the electrode under normal electrocrystallisation conditions and, as explained before, iodine oxidation resulted in a more convenient way to prepare the neutral complexes

Table 1. Half wave, $E_{1 / 2}$, potentials $(\mathrm{mV})$ of gold and nickel complexes based on bisdithithiphene ligands relative to ferrocene/ferrocenium. ${ }^{[a]}$

\begin{tabular}{|c|c|c|c|c|}
\hline & $\mathrm{E}_{1 / 2}^{1}(\mathrm{mV})^{[\mathrm{b}]}$ & $\mathrm{E}_{1 / 2}^{2}(\mathrm{mV})^{[\mathrm{c}]}$ & $E_{1 / 2}^{3}(m V)^{[d]}$ & Ref \\
\hline $\mathrm{Ni}(\alpha-b p-t p d t)_{2}$ & -1313 & -527 & - & This work \\
\hline $\mathrm{Ni}(\alpha-\mathrm{m}-\mathrm{tpdt})_{2}$ & -1122 & -384 & +601 & [10] \\
\hline $\mathrm{Au}(\alpha-b p-t p d t)_{2}$ & - & -300 & +591 & This work \\
\hline $\mathrm{Ni}(\alpha-\text { tb-tpdt })_{2}$ & -1119 & -164 & - & This work \\
\hline $\mathrm{Au}(\alpha-\mathrm{m}-\mathrm{tpdt})_{2}$ & & -78 & & [10] \\
\hline $\mathrm{Au}(\alpha-\mathrm{tb}-\mathrm{tpdt})_{2}$ & - & -48 & +530 & This work \\
\hline $\mathrm{Ni}(\alpha-\mathrm{tpdt})_{2}$ & -630 & +136 & - & [12] \\
\hline $\mathrm{Au}(\alpha-\mathrm{tpdt})_{2}$ & - & +242 & - & [3] \\
\hline
\end{tabular}


[a] $\mathrm{Ag} / \mathrm{AgNO}_{3}$ as reference electrode, dichloromethane as solvent, and scan rate $100 \mathrm{mV} / \mathrm{s}$. The $\mathrm{Fc} / \mathrm{Fc}^{+}$couple was used as internal reference and the values in the table are normalized relatively to it. ${ }^{[13]}$

[b] $E_{1 / 2}^{1}=$ dianionic / monoanionic,

[c] $\mathrm{E}_{1 / 2}^{2}=$ monoanionic / neutral

[d] $\mathrm{E}_{1 / 2}^{3}=$ neutral / cationic

\section{X-Ray Crystallography}

With exception of the neutral compounds $\mathbf{5}$ and $\mathbf{6}$, for each ligand and oxidation state, the $\mathrm{Ni}$ and $\mathrm{Au}$ compounds are isostructural with virtually identical packing pattern. For sake of simplicity only the gold compound is described and details of the Nickel analogues can be found in supplementary material.

Compound $\mathbf{1}$ is isostructural to $\mathbf{2}$ and they crystallize in the monoclinic system, space group $\mathrm{C} 2 / \mathrm{c}$. The asymmetric unit contains half monoanionic complex, $\left[\mathrm{M}(\alpha-\text { tbtpd })_{2}\right]^{-}$, and half $\mathrm{TPP}^{+}$ cation, with the metal atom at an inversion centre and the $P$ atom at an inversion 2-fold axis. The gold and nickel complexes presents the usual square planar coordination geometry, remaining essentially planar with exception of the butyl groups, with angles and bond distances in the usual range of monoanionic dithiothiophenic dithiolates. ${ }^{[3][10][12]}$ The thiophenic sulfur atom S3 is found disordered among two positions (S3/S3A, $62 / 38 \%$ and $68 / 32 \%$ for 1 and 2, respectively) corresponding to positional disorder (Figure S3). The $\mathrm{TPP}^{+}$cation also presents the usual geometry (TableS3 and Figure S3/S4).

The crystal structure is composed by chains along $c$ of the $[\mathrm{M}(\alpha-$ tbtpd $\left.)_{2}\right]^{-}$anions connected side-by-side by short S3 $\cdots$ S3 contacts and S2 $\cdots 6 \mathrm{H}-\mathrm{C} 6$ Hydrogen bonds (Fig. 2 and Table S4). The anions of nearby chains are almost perpendicular to each other, making an angle of $80.6^{\circ}$. This arrangement leads to tunnels that are occupied by the TPP ${ }^{+}$cations connected to the anions by $\mathrm{S}_{\text {cood }}{ }^{\cdots} \mathrm{H}-\mathrm{C}$ hydrogen bonds (Table S4).

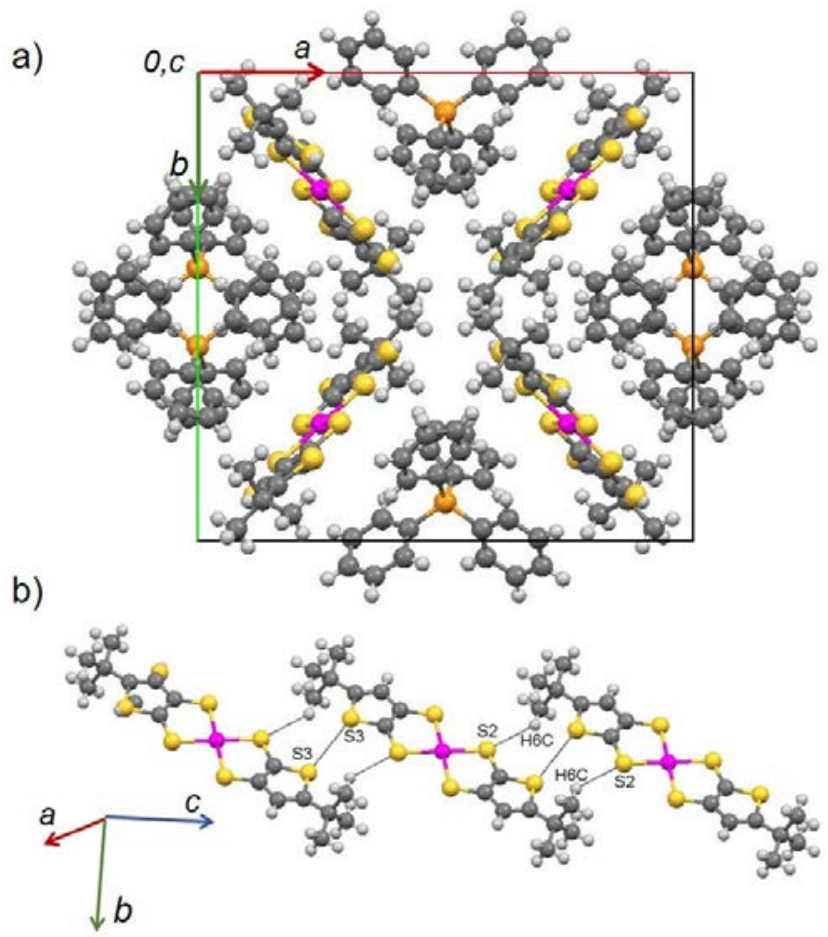

Figure 2. Crystal structure of 1 : a) viewed along $c ;$ b) detail of the anionic chains, with thin lines highlighting the shortest atomic distances.

Compounds $\mathbf{3}$ and $\mathbf{4}$ are isostructural, and crystallize in the triclinic system, space group P-1. The asymmetric unit contains two monoanianic complexes $\left[\mathrm{M}(\alpha \text {-bi-isop-tpd })_{2}\right]^{]}$, with the metal at an inversion centre and a $\mathrm{TPP}^{+}$molecule at a general position. The metal complexes in these compounds present a square planar coordination geometry with a slight chair type distortion (FigureS5). Bond distances and angles are identical to those of compounds 1 . and 2.

The crystal structure is composed by X-shaped anionic chains, running parallel to $a-c$. Along the chains, the average molecular plane of the two non-equivalent dithiolate complexes make an angle of $79.2^{\circ}$ and the molecules are connected by short $S \cdots S$ contacts (Figure 3 , Table S9). TPP ${ }^{+}$cations occupy the empty space between anions and are connected to them through $\mathrm{S}_{\text {coord. }}$. $\mathrm{H}-\mathrm{C}$ and $\mathrm{C}_{\text {double-bond }}{ }^{\prime} \mathrm{H}-\mathrm{C}$ hydrogen bonds (Table S9). 


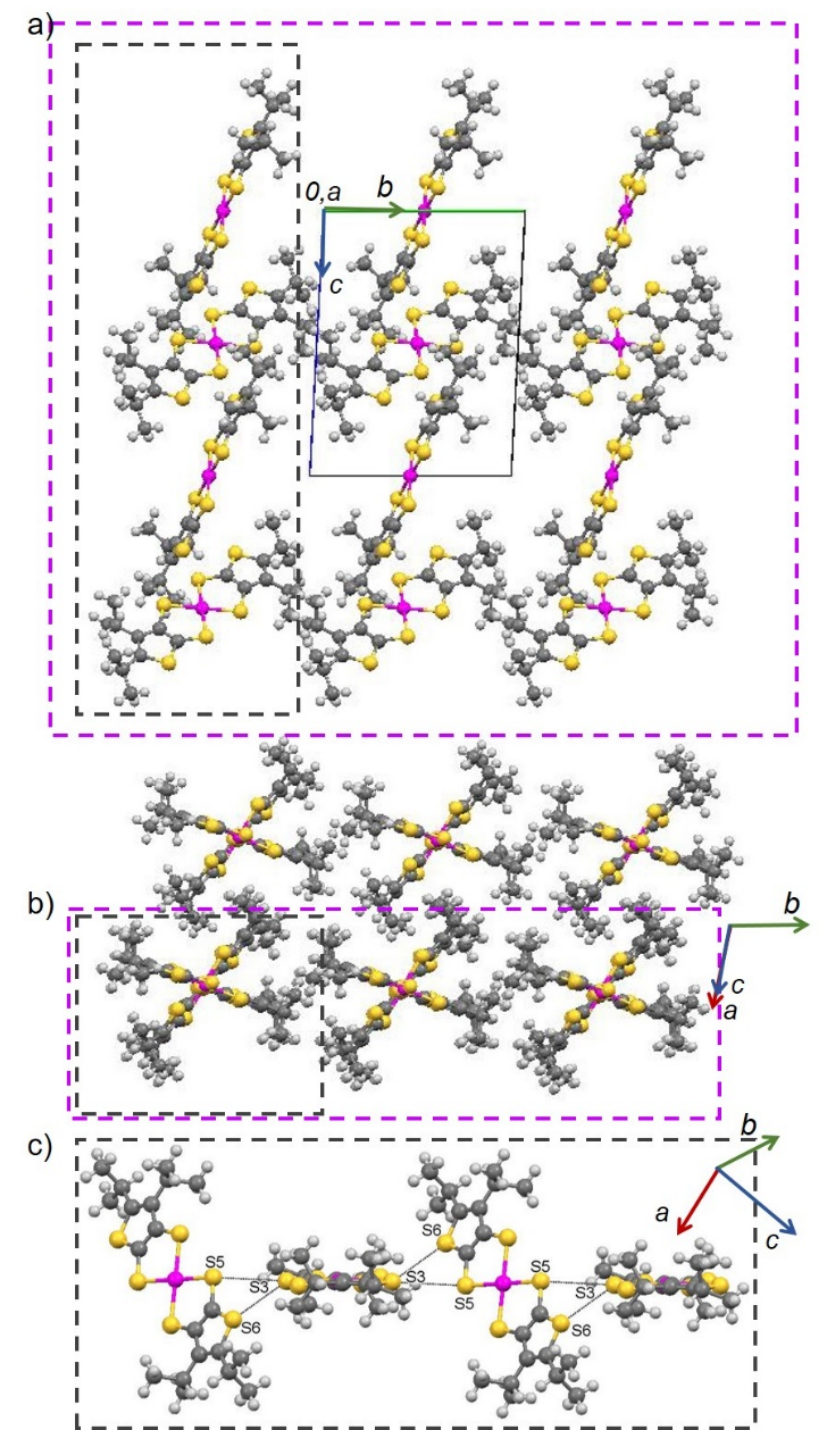

Figure 3. Crystal structure of 3 a) viewed along $a$. ; b) along the (a-c, b), highlighting the X-chains and $c$ ) detail of one $X$-chain and the short $S \cdots S$ contacts between anions. The $\mathrm{TPP}^{+}$cations were omitted for clarity. The dotted grey linw represents one $\mathrm{X}$-chain. The dotted rose line represents one layer of X-chains.

Compound $\mathbf{5}$ crystallizes in the monoclinic system, space group $\mathrm{P} 2_{1} / \mathrm{n}$. The unit cell contains one neutral molecule of [Au( $\alpha-b p-$ tpdt) $]^{0}$ at a general position. The neutral complex presents the usual square planar coordination geometry (Figure 4 and FigureS7). ${ }^{[7][14]}$ A detailed analysis of the bond lengths of the metal bisdithiolene core reveals a significant asymmetry between the two ligands (Table S13) supporting the localization of the unpaired electron in one ligand, as recently found in $\left[\mathrm{Au}(\mathrm{dm} \text {-dddt) })_{2}\right]$ (dm-dddt= 5,6-dimethyl-5,6-dihydro-1,4-dithiin2,3-dithiolate). ${ }^{15}$ Besides the slight dihedral angle $\left(11^{\circ}\right)$ due to a folding through S1-S2 atoms, the "oxidized" $\alpha$-tb-tpdt ligand also denotes shorter $\mathrm{S}_{\text {coord }} \mathrm{C}$ bonds and more regular $\mathrm{C}-\mathrm{C}$ bonds in the thiophene ring, when compared with the other $\alpha$-tb-tpdt ligand, that stays planar and with bond distances closer to the monoanionic specie in $\mathbf{1}$ The thiophenic sulfur atoms are found disordered almost equaly among two positions: S5/S5A and S6/S6A, with $56 / 44 \%$ and $54 / 46 \%$, respectively, for $\mathbf{5}$, and
S3/S3A and S6/S6A, with $55 / 45 \%$ and $58 / 42 \%$, respectively, in the case of 6 .
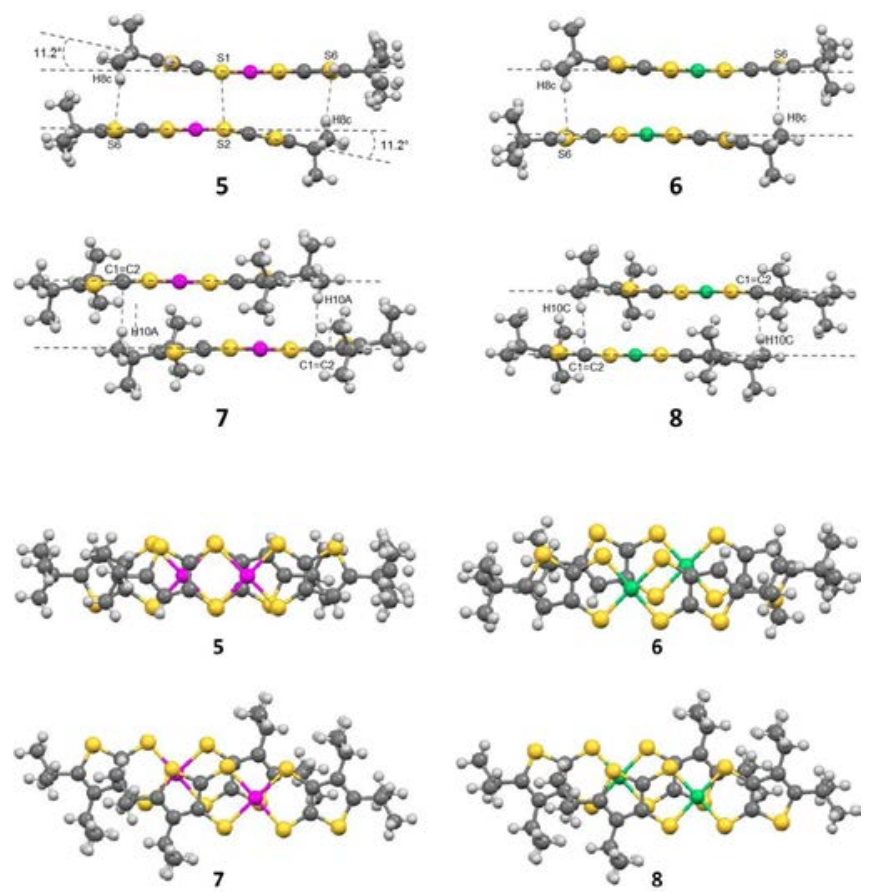

Figure 4. Molecular diagrams showing the different overlapping modes of the neutral complexes in $\mathbf{5 - 8}$.

The neutral molecules are associated in pairs related by a inversion center, through two very short $\mathrm{S} 1 \cdots \mathrm{S} 2^{*}, \mathrm{~S} 2 \cdots \mathrm{S} 1^{*}$ contacts $(3.275 \AA$, *symm. op. 1-x,1-y,-z) connecting ligands with different electronic densities. These pair of molecules are arranged in the crystal structure in chains interacting throughout several side-by-side $\mathrm{S}_{\text {coord }}{ }^{\prime} \mathrm{S}_{\text {coord }}$ short contacts, giving rise to double chains along a. Nearby double chains have molecules tilted in alternated orientation and molecules make an angle of $63.9^{\circ}$ (Figure 5).

Compound $\mathbf{6}$ is not isostructural to $\mathbf{5}$ although sharing a common molecular packing pattern (Figure 6). The nickel complex has a central core more planar than the gold analogue (Figure 4), without the asymmetry in bond lengths and folding dihedral angle of the related Au complex (TableS15), as expected for a molecule with an even number of electrons. The analysis of the bond lengths in the neutral complex compared with the anionic one reveals that there is mainly a significant shortening of the $\mathrm{S}_{\text {coord }} \mathrm{C}$ bonds, denoting a ligand centered oxidation process. In 6 the dimers are associated by a long sulfur over metal contacts, at $3.780 \AA$, rather than ligand-ligand interactions, as in $\mathbf{5}$ (Figure $4)$. In the crystal structure the dimmers are arranged in layers, connecting with each other by short $\mathrm{S} 2 \cdots \mathrm{S} 2{ }^{*} \mathrm{~S} 3{ }^{\cdots} \mathrm{S}^{*}{ }^{*}$ contacts (3.682 A, *symm. op. -x,-y,1-z and $3.443 \AA$, *symm. op. 1-x,-y,-z, respectively). Molecules in different layers are rotate $72^{\circ}$ (Figure $6)$. 


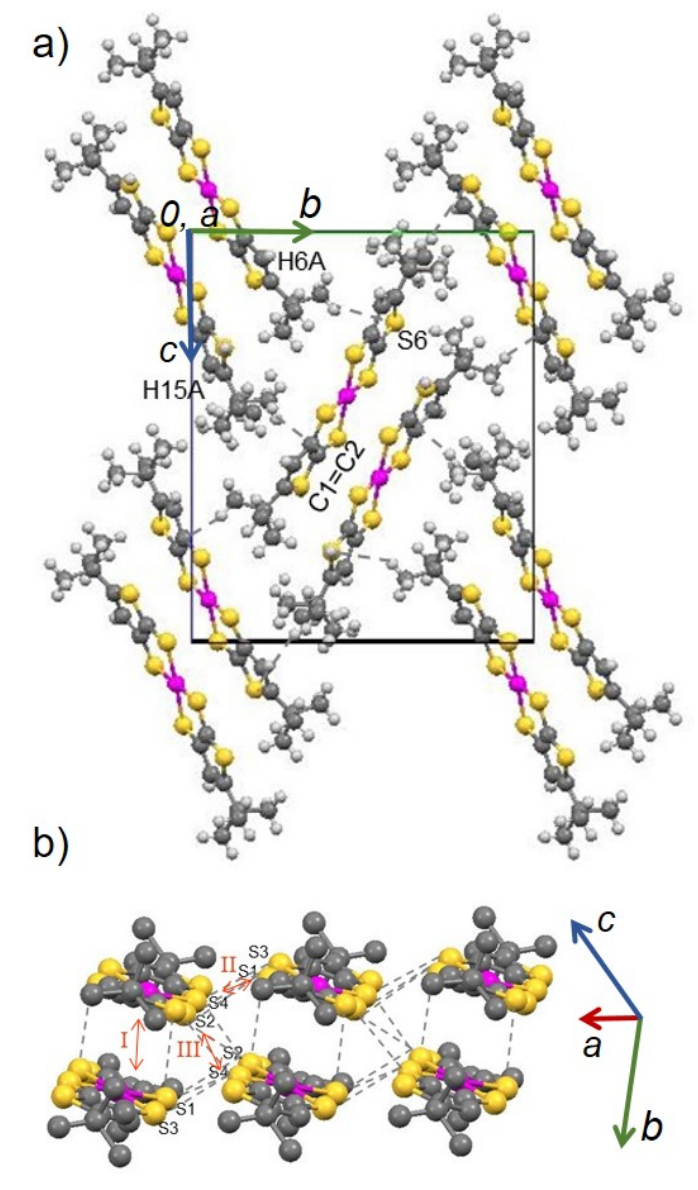

Figure 5. Crystal structure of $\mathbf{5}$ a) viewed along $a$ and b) Partial view showing pairs of molecules arrangement in a double-chain.

Compound $\mathbf{7}$ is isostructural with $\mathbf{8}$, crystallizing in the triclinic system, space group P-1. The unit cell contains one neutral complex $\left[\mathrm{M}(\alpha \text {-tb-tpdt })_{2}\right]^{0}$ with the metal atom at an inversion center. These neutral complexes present the usual square planar coordination geometry and with exception of the isopropyl substituents are essentially planar (Figure 4). The bond distances are in the range for other gold and nickel neutral compounds. ${ }^{[7][14]}$ When the neutral complexes of both $\mathrm{Au}$ and $\mathrm{Ni}$ are compared with the corresponding monoanions it's clear that the most sensitive bond lengths to the electron removal are the Scoord-C, and the M-S distances are not significantly affected, as previously found in the related methyl substituted complexes. ${ }^{[10]}$ a)
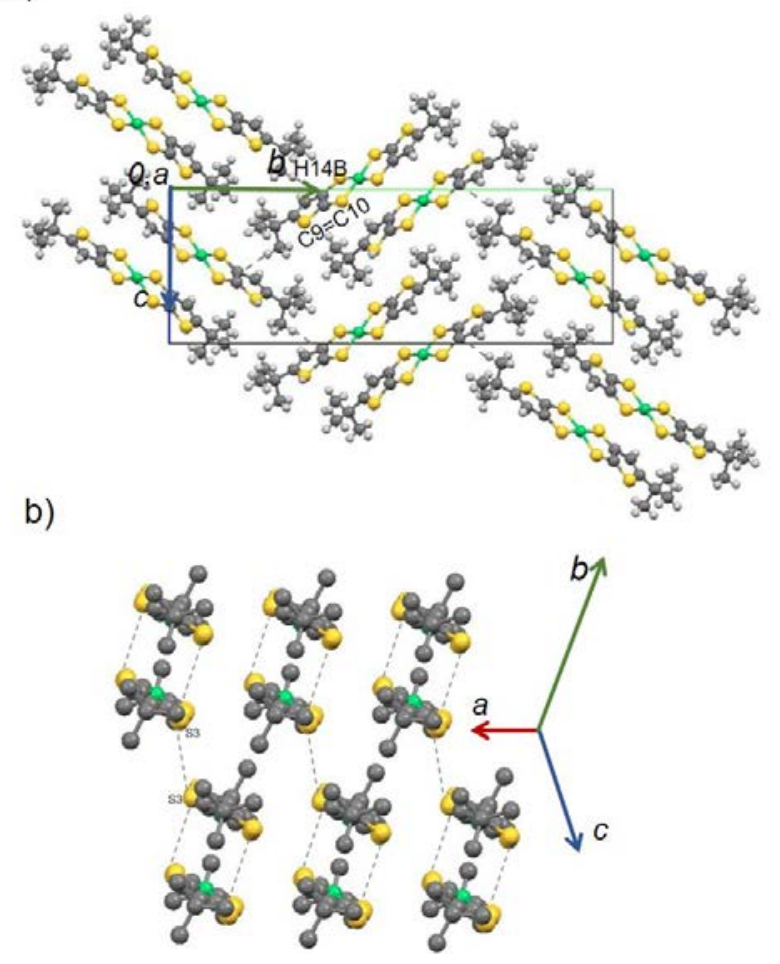

Figure 6. Crystal structure of 6 a) viewed along $a$ and b) Partial view showing the pair arrangement in layers.

The crystal structure is composed of regular columns of neutral complexes $\left[\mathrm{Au}(\alpha-\text { tbtpd })_{2}\right]^{0}$, stacked face-to-face along a (Figure 7). The overlap of the molecules in these stacks involves a displacement essentially along the long axis of the complexes so that the thiophenic sulphur atom of one molecule lies above the metal atom of the next one (Figure 4). This type of overlap with unusually long displacement of the molecules is certainly due to the stereochemical constrains imposed by the alkyl substituents. Also as a consequence of the bulky substituents neither the interplanar distance between central bisdithiolene atoms in a stack $(3.483 \AA$ for $\mathrm{Au}$ and $3.623 \AA$ for $\mathrm{Ni}$ ) nor the shorter contacts between molecules in neighboring columns

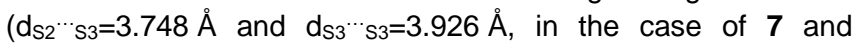
$\mathrm{d}_{\mathrm{s} 2}{ }^{\mathrm{s} 3} \mathrm{~s}=3.725 \AA$ and $\mathrm{d}_{\mathrm{s} 3}{ }{ }_{\mathrm{s} 3}=3.883 \AA$, in the case of 8 ) are below the sum of the van der Waals radii.

An interesting question is raised about the origin of the ligand asymmetry observed in $\mathbf{5}$ while $\mathbf{7}$ remains symmetric. Recently it has been suggested that. ${ }^{16}$ this is governed not only by the balance between the electronic coupling between the two ligands, $\mathrm{H}$, and the so called Marcus reorganisation energy $\lambda$, but also by intermolecular interactions in the solid state. In this case in view of the similarity of the isopropyl and ter-butyl substituted ligands the first parameters are expected to be essentially the same. Therefore the observed differences should be ascribed to the role of the intermolecular interactions in the solid, providing a clear illustration of the predicted stabilization of the symmetrical configuration by SOMO 'SOMO interactions in case of the formation of regular stacks, ${ }^{[15]}$ as in the isopropyl substituted complex $\mathbf{7}$, while the terbuthyl substituents in $\mathbf{5}$ do 
not allow a regular stacking with good intermolecular interaction and therefore the stable configuration is asymmetric.

a)

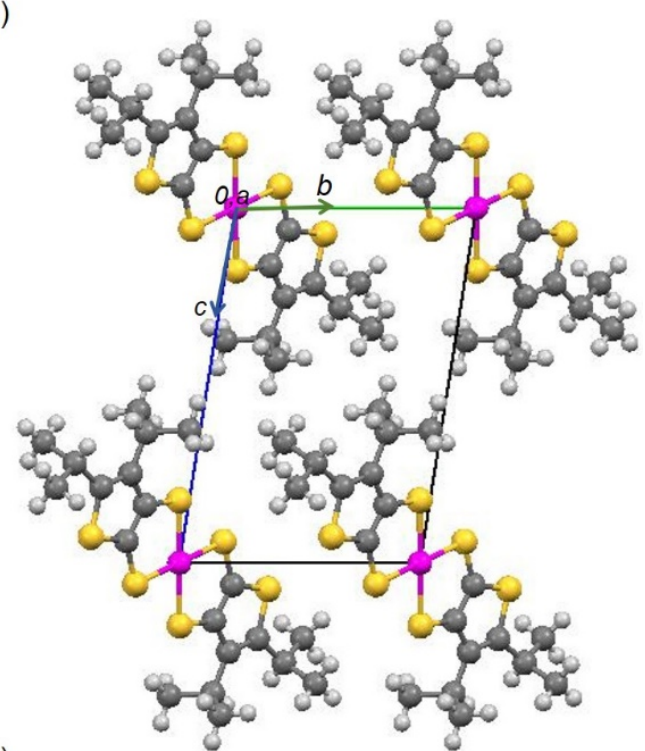

b)

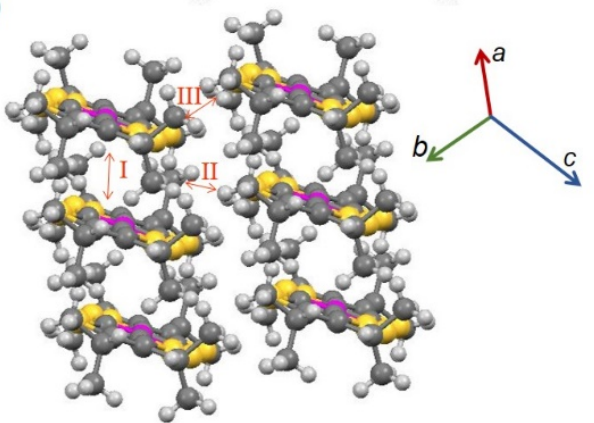

Figure 7. Crystal structure of 7 a) viewed along $a$; b) partial view showing two neighbouring stacks, viewed along the molecular longest axis.

\section{Electrical Transport Properties}

The electrical conductivity, measured in single crystals, at room temperature for 5-8 is rather small, ranging from $10^{-8}$ to $5 \times 10^{-5} \mathrm{~S} / \mathrm{cm}$. These low values typical of insulators, can be understood as a consequence of the relatively large HOMOLUMO gap of these complexes preventing any overlap of the corresponding bands in solid state. The neutral gold complexes present one electron in the HOMO which in the solid state, leading in most cases to a half filled band behaving as Mott insulating system. This is confirmed by an analysis of the solid state intermolecular interactions calculated for compounds $\mathbf{5}$ and 7 using the extended Hückel approximation and a double- $\xi$ basis set. In both cases three type of different possible interactions were considered between molecules along the chains and between nearby chains as indicated in figures 6 and 7. In the case of $\mathbf{5}$, the calculations show that the strongest interaction $(\mathrm{I})$ is between pair of molecules, overlapped face-toface, one order of magnitude higher than the interactions (II and III) between molecules placed side-by-side along the chains. In compound 7, the strongest Interactions occurs between molecules stacked in the same collumn(I) with much smaller interactions between molecules in neighboring stacks (II and III as shown in fig. 7).

\begin{tabular}{|c|c|c|c|}
\hline Compound & Interaction & $\mathrm{S}_{\mathrm{ij}} \times 10^{-3}$ & $\mathrm{H}_{\mathrm{ij}}(\mathrm{meV})$ \\
\hline \multirow[t]{3}{*}{5} & 1 & 20.3 & 487.2 \\
\hline & II & 2.4 & 56.8 \\
\hline & III & 0.8 & 18.1 \\
\hline \multirow[t]{3}{*}{7} & 1 & 13.5 & 286.8 \\
\hline & II & 1.5 & 33.8 \\
\hline & III & 0.1 & 0.8 \\
\hline
\end{tabular}

\section{Magnetic Properties}

The monoanionic $\mathrm{Ni}$ and the neutral Au complexes with an odd number of electrons are expected to be paramagnetic while the monoanionic $\mathrm{Au}$ and neutral $\mathrm{Ni}$ complexes are expected to be diamagnetic. The paramagnetic susceptibility $\chi_{P}$ of compounds was obtained in the range $2-300 \mathrm{~K}$ from measurements with a SQUID magnetometer after a correction for diamagnetism estimated from tabulated Pascal constants. As shown in Figure 8 the paramagnetic nickel compounds 2 and $\mathbf{4}$ present at room temperature values of $\chi_{\mathrm{p}} \mathrm{T}$ product of 0.41 and $0.38 \mathrm{emuK} / \mathrm{mol}$, corresponding to effective magnetic moments of $1.79 \mu_{\mathrm{B}}$, and $1.74 \mu_{\mathrm{B}}$, respectively, close to the expected value of $1.73 \mu_{\mathrm{B}}$ for a $S=1 / 2$ systems with $\mathrm{g}=2$.

$\chi_{p} T$ of $\mathbf{2}$ is almost temperature independent from room temperature until circa $30 \mathrm{~K}$ with a small increase below this temperature to reach $0.43 \mathrm{emu} \mathrm{K} / \mathrm{mol}$. A small but more significant and gradual increase of $\chi_{p} T$ is observed upon cooling in compound $\mathbf{4}$ with reaching at $20 \mathrm{~K}$ a maximum comparable to 2 followed by a decrease to $0.41 \mathrm{emuK} / \mathrm{mol}$ at $15.5 \mathrm{~K}$. This increase of $\chi_{p} T$ upon cooling denotes the presence of dominant ferromagnetic Interactions probably mediated by short S3 $\cdots$ S6 contacts while in $\mathbf{2}$ the anions are more isolated.

The neutral gold complex in compound $\mathbf{5}$ was found to be essentially diamagnetic with a weak paramagnetic contribution corresponding to less than $4 \%$ of $S=1 / 2$ which is in agreement with a strong antiferromagnetic interaction due to the structural dimerization of the complexes as described above. 


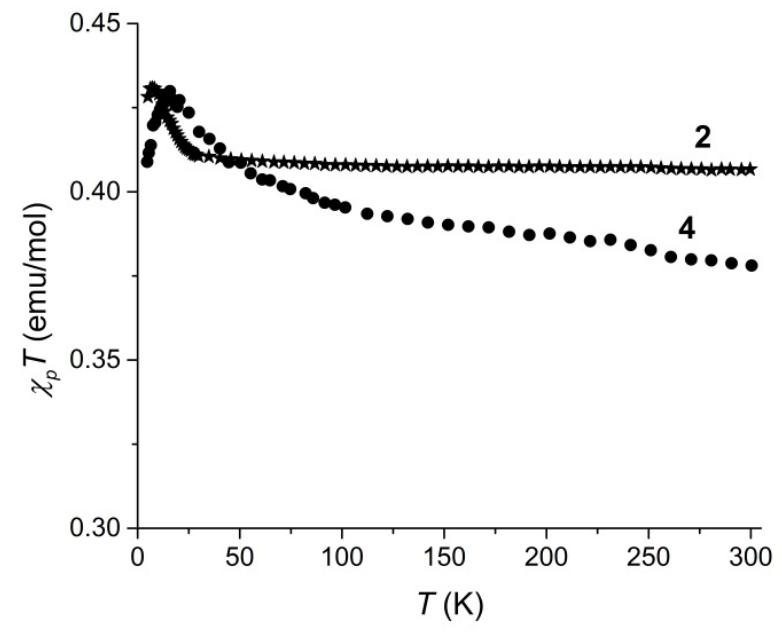

Figure 7. Temperature dependence of the $\chi_{\mathrm{p}} \mathrm{T}$ product of compounds $\mathbf{2}$ (stars), 4 (circles), and 6 (triangles)

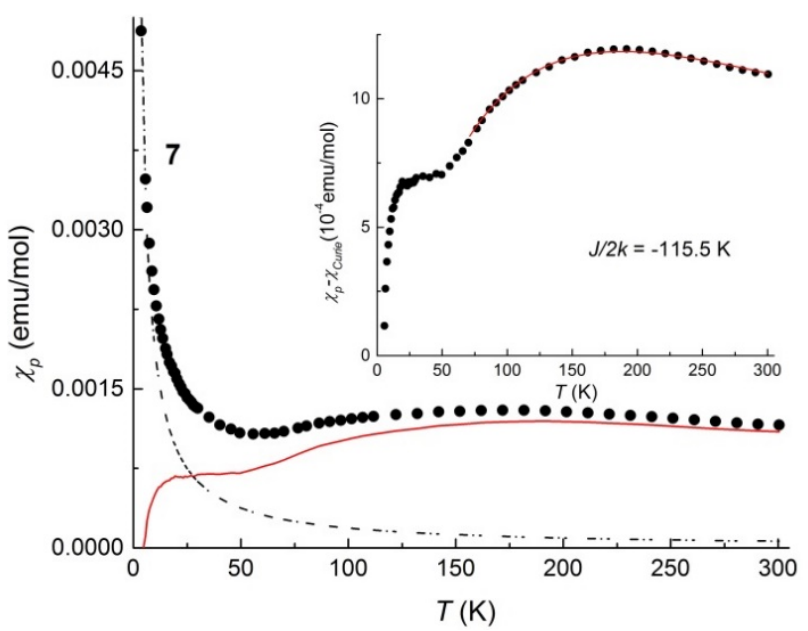

Figure 8. Temperature dependence of the paramagnetic susceptibility $\chi_{p}$ of $\mathbf{7}$. The doted black line is a Curie contribution, $X_{\text {curie, }}$ corresponding to $4.8 \%$ of $S=1 / 2$ spins, and the red solid line is the result after subtracting $X$ curie (see inset). The red solid line in the inset is the fit of the Bonner Fisher model with $\mathrm{J}=-115.5 \mathrm{~K}$.

The paramagnetic gold compound 7 that presents the neutral complexes in regular stacks shows a significant paramagnetic susceptibility. As shown in Figure 8 (above), upon cooling there is a broad maximum in the paramagnetic susceptibility around $200 \mathrm{~K}$, followed by a decrease upon cooling until $\sim 50 \mathrm{~K}$ where it reaches a minimum. At lower temperatures, there is an increase of susceptibility ascribed to a dominating Curie-like tail corresponding to approximately $4.8 \% \quad \mathrm{~S}=1 / 2$ spins. By subtracting the Curie contribution the resulting magnetic susceptibility curve, $X_{p^{-}} X_{\text {curie }}$, (inset of Figure 8) shows at high temperatures a behavior which is reminiscent from that expected for a uniform antiferromagnetic chain in agreement with the structure based on uniform stacks of paramagnetic molecules.
Indeed the results in the $50-300 \mathrm{~K}$ range can be fitted to a Bonner-Fisher model using the following equation valid for $2 k T / J>0.5,{ }^{[21]}$

$$
\begin{aligned}
& X=(\mathrm{C} / T) \cdot\left(\left(0.25+0.149445(J / 2 k T)+0.30094(J / 2 k T)^{2}\right) /(1+1.9862(J /\right. \\
& \left.\left.2 k T)+0.68854(J / 2 k T)^{2}+6.0626(J / 2 k T)^{3}\right)\right)
\end{aligned}
$$

with an antiferromagnetic interaction $\mathrm{J} / 2 \mathrm{~K}=-115.5 \mathrm{~K}$ (solid line ). In the lower temperature region $(T<40 \mathrm{~K})$ the paramagnetic susceptibility shows a plateau, and then below $25 \mathrm{~K}$ a faster decrease towards zero, suggesting an AF transition which may occur as a consequence of additional interchain AF interactions. In fact considering the interactions previously mentioned between stacks, the system is expected to be not strictly one dimensional at low temperatures, but instead behave as an anisotropic two dimensional system, allowing the occurrence of a transition. This possibility of an AF transition was confirmed by AC susceptibility measurements at different frequencies showing the absence of signal in the out-of-phase component, $\chi^{\prime \prime}$, in contrast to the in-phase component, $\chi^{\prime}$ that shows a peak occurring at $\sim 25 \mathrm{~K}$ (Figure SI5).). The full characterization of this transition requires however additional measurements in single crystals which could not be performed at present stage.

The paramagnetic nature of the nickel compounds 2 and $\mathbf{4}$ is confirmed by their e.p.r. spectra. In frozen solutions at $77 \mathrm{~K}$ spectra consist in a single line $50 \mathrm{G}$ and $20 \mathrm{G}$ wide centered at $g=2.0425$ and 2.0485 respectively. The e.p.r. spectra of $a$ polycrystalline sample show a signal typical of rhombic system, characteristic of monoanionic nickel bisdithiolene complexes ${ }^{[12][22][23]}$ with $g_{1}, g_{2}$ and $g_{3}$ values of 2.0887, 2.032 and 2.024, for 2 and 2.0915, 2,0521 and 2.0340 for 4 . The neutral gold complexes in $\mathbf{5}$ and $\mathbf{7}$ were found to be e.p.r. silent in the solid state. However in dichloromethane solution they showed a single line $25 \mathrm{G}$ wide centered at $\mathrm{g}=2.0019$ and 2.010 respectively.

\section{Conclusions}

In this paper the synthetic route to prepare the first members of two new families of complexes based on ter-buthyl and diisopropyl substituted thiophedithiolate ligand, [M( $\alpha$-tb-tpdt $\left.)_{2}\right]^{\mathrm{x}}$ and $\left[\mathrm{M}(\alpha-\mathrm{dp}-\mathrm{tpdt})_{2}\right]^{\mathrm{x}}, \mathrm{M}=\mathrm{Au}, \mathrm{Ni}$ and $\mathrm{x}=-1$ and 0 was established. As expected, the effect of appending alkyl groups to the thiophene ring renders the new complexes more soluble in common organic solvents and easier to be oxidized to a stable neutral specie than the related non substituted complexes. In the case of the gold complexes, even the cationic species becomes accessible at relatively low potentials. But this gain in solubility and easier access to differently oxidized species is associated with a loss of the electrical conductivity. This loss of conductivity is a consequence of an inefficient molecular overlapping in solid state due to stereochemical effects of the bulky alkyl substituents

The crystal structure data of the neutral gold complexes, $\mathbf{5}$ and $\mathbf{7}$, both with an odd number of electrons and similar peripheral alkyl groups, provide a clear illustration of the role of the intermolecular interactions in the stabilization of SOMO “SOMO interactions. The small difference between the alkyl substituents is enough to allow a more significant intermolecular interaction in 
5 than in 7, resulting in a stable asymmetric configuration, with the unpaired electron centered in one of the ligands. In compound 7, the dimerization of the complexes is prevented, leading to a regular stacking of paramagnetic complexes with a symmetrical configuration. The paramagnetic [Au( $\left.\alpha-d p-t p d t)_{2}\right]$ units present strong antiferromagnetic interactions undergoing an AFM transition at ca. $25 \mathrm{~K}$.

\section{Experimental Section}

General experimental conditions: All manipulations were carried out under strict anaerobic conditions under dry nitrogen, unless otherwise stated. All solvents were purified following standard procedures. Other chemicals were commercially obtained and used without any further purification. Compound II, was prepared following a previously reported procedure. Synthesis of 5,6-diisopropylthieno[2,3-d][1,3]dithiol-2-one Compound III: $0.33 \mathrm{~g}(2.5 \mathrm{mmol})$ aluminium chloride in $6 \mathrm{~mL}$ dichlorometane was cooled to $-78^{\circ} \mathrm{C}$ in nitrogen atmosphere and a mixture of $0.25 \mathrm{~g}(1.4 \mathrm{mmol})$ thieno[2,3-d][1,3]dithiol-2-one (I) and $0.26 \mathrm{~mL}$ (2.8 mmol) 2-chloropropane in $3 \mathrm{~mL}$ dichlorometane was added dropwise. After stirring for $1 \mathrm{~h}$, the reaction mixture was allowed to warm up to $10{ }^{\circ} \mathrm{C}$ and stirred for $4 \mathrm{~h}$, maintaining the temperature between -10 and $5^{\circ} \mathrm{C}$. The product was poured into ice water, neutralized with sodium hydrocarbonate and extracted with dichlorometane. After drying with magnesium sulphate, the solvent was evaporated. The crude product was purified by column chromatography using n-hexane/ethyl acetate (10:1) as eluent and further recrystallized from hexane to yield $0.198 \mathrm{~g}$ (60\%)of III as white needles. M.p. $90.1-90.6^{\circ} \mathrm{C} .{ }^{1} \mathrm{H}$ NMR $(300 \mathrm{MHz}$, CDCl3): $\delta 3.38$ (hept, $\mathrm{J}=6.8 \mathrm{~Hz}, 1 \mathrm{H}$ ), 3.20 (hept, $\mathrm{J}=7.0 \mathrm{~Hz}, 1 \mathrm{H}$ ), 1.32 (s $3 \mathrm{H}), 1.30$ (s, 3H), $1.26(\mathrm{~s}, 3 \mathrm{H}), 1.24$ (s, 3H). 13C NMR (75 MHz, CDCl3): $\delta$ 194.84, 147.69, 137.16, 125.31, 118.93, 28.78, 27.68, 25.16, 21.63. Elemental analysis calcd (\%) for C11H14OS3: C 51.13, H 5.46, S 37.22; found C 52.01, H 6.20, S 38.20.

Syhthesis of TPP[Au( $\alpha$-tbtpdt) 2 , (1): In the glovebox, 90mg $(0.4 \mathrm{mmol})$ of ligand II was added to a solution of $108 \mathrm{mg}(2 \mathrm{mmol})$ sodium methoxide in methanol $(5 \mathrm{~mL})$ and stirred for $10 \mathrm{~min} .73 .8 \mathrm{mg}(0.2 \mathrm{mmol})$ potassium tetrachloroaurate was dissolved in methanol $(1 \mathrm{~mL})$ and added to the reaction mixture. The dark brown solution obtained is stirred at room temperature for $15 \mathrm{~min}$. The inorganic precipitate was removed by filtration and the liquor added to a solution of $81.9 \mathrm{mg}(0.2 \mathrm{mmol})$ tetraphenylphosphonium bromide in methanol $(1 \mathrm{~mL})$. A pale green precipitate was formed. The mixture was removed from the glovebox, the solid was filtered, washed with cold methanol and recrystallized from acetone:2-propanol 3:1 to afford $140 \mathrm{mg}$ (38\% yield) of pale green needles. Elemental analysis calcd (\%) for $\mathrm{C}_{40} \mathrm{H}_{40} \mathrm{AuPS}_{6}$ : C 51.05, H 4.28, S 20.44; found C 50.90, H 4.36, S 20.44 .

Syhthesis of TPP[Ni( $\alpha$-tbtpdt $\left.)_{2}\right],(2): I n$ the glovebox, 90mg $(0.4 \mathrm{mmol})$ ligand II was added to a solution of $108 \mathrm{mg}$ ( $2 \mathrm{mmol}$ ) sodium methoxide in methanol $(5 \mathrm{~mL})$ and stirred for $10 \mathrm{~min}$. $46.4 \mathrm{mg} 0.2 \mathrm{mmol}$ ) nickel chloride hexahydrate was dissolved in methanol $(1 \mathrm{~mL})$ and added to the reaction mixture. The red solution obtained is stirred at room temperature for 15 min. The inorganic precipitate was removed by filtration and the liquor added to a solution of $163.8 \mathrm{mg}(0.4 \mathrm{mmol})$ tetraphenylphosponium bromide in methanol $(1 \mathrm{~mL})$. No precipitate was formed and the solution remained red. The mixture was removed from the glovebox and stirred in the presence of oxygen, affording a bright green precipitate, which was filtered, washed with cold methanol and recrystallized from acetone:2propanol 3:1 to afford $135.5 \mathrm{mg}(43 \%)$ of dark green needles. Elemental analysis calcd (\%) for $\mathrm{C}_{40} \mathrm{H}_{40} \mathrm{NiPS}_{6}$ : C 59.85, H 5.02, S 23.96; found C 58.87 , H 5.75, S 23.26 .

Synthesis of TPP[Au(a-(bptpdt) 2 , (3):In the glovebox, 100mg (0.4 $\mathrm{mmol}$ ) ligand III was added to a solution of $120 \mathrm{mg}(2 \mathrm{mmol})$ sodium methoxide in methanol $(5 \mathrm{~mL})$ and stirred for 30-40min. 73.11mg $(0.2$ $\mathrm{mmol}$ ) potassium tetrachloroaurate was dissolved in methanol $(1 \mathrm{~mL})$ and added to the reaction mixture. The brown solution obtained is stirred at room temperature for $15 \mathrm{~min}$. A solution of $81.13 \mathrm{mg}(0.2$ mmol)tetraphenylphosphonium bromide in methanol $(1 \mathrm{~mL})$ is then added to the previous reaction mixture, without stirring. A green-brown precipitate is formed and the mixture is kept in the glovebox for additional 2 hours. The precipitate dissolves and the mixture is removed from the glovebox and allowed to oxidize with atmospheric oxygen. Brown crystals are formed immediately, the mixture is kept in the fridge overnight and then the crystals are filtered and washed with cold methanol, to afford $118 \mathrm{mg}(31 \%)$ of brown needles. Elemental analysis calcd (\%) for $\mathrm{C}_{44} \mathrm{H}_{48} \mathrm{AuPS}_{6}$ : C 53.00, H 4.85, S 19.29; found C 52.58, H 4.71, S 18.51.

Synthesis of TPP[Ni( $\alpha$-(bptpdt) $)_{2}$, (4): In the glovebox, 100mg (0.4 $\mathrm{mmol}$ ) ligand III was added to a solution of $120 \mathrm{mg}(2 \mathrm{mmol})$ sodium methoxide in methanol $(5 \mathrm{~mL})$ and stirred for 30-40min. $45.99 \mathrm{mg}(0.2$ $\mathrm{mmol})$ nickel chloride hexahydrate was dissolved in methanol $(1 \mathrm{~mL})$ and added to the reaction mixture. The dark red solution obtained is stirred at room temperature for $15 \mathrm{~min}$. A solution of $162.29 \mathrm{mg}(0.4 \mathrm{mmol})$ tetraphenylphosponium bromide in methanol $(1 \mathrm{~mL})$ is then added to the previous reaction mixture, without stirring. No precipitate is formed, the mixture is kept in the glovebox for additional 2 hours and then removed and allowed to oxidize with atmospheric oxygen. Green crystals are formed immediately, the mixture is kept in the fridge overnight and then the crystals are filtered and washed with cold methanol, to afford $100 \mathrm{mg}$ (30\%) of green needles. Elemental analysis calcd (\%) for $\mathrm{C}_{44} \mathrm{H}_{4}{ }_{8} \mathrm{NiPS}_{6}$ : C 61.53, H 5.63, S 22.40; found C 61.64, H 5.67, S 21.99.

Syhthesis of [Au(a-tbtpdt)2], (5): A solution of $13.8(0.05 \mathrm{mmol}) \mathrm{mg}$ iodide in $2 \mathrm{~mL}$ dichloromethane is slowly added to a solution containing $50 \mathrm{mg}(0.05 \mathrm{mmol})$ of $1 \mathrm{in} 4 \mathrm{~mL}$ dichloromethane. A dark precipitate is formed immediately, which is centrifuged and washed several times with cold dichloromethane, yielding $15.77 \mathrm{mg}$ of dark brown needles (49\%). Elemental analysis calcd (\%) for $\mathrm{C}_{16} \mathrm{H}_{20} \mathrm{AuS}_{6}$ : C 31.94 , H 3.35, S 31.97; found C 32.36, H 3.74, S 32.50 .

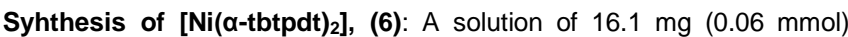
iodide in $2 \mathrm{~mL}$ dichloromethane is slowly added to a solution containing $50 \mathrm{mg}(0.06 \mathrm{mmol})$ of 2 in $4 \mathrm{~mL}$ dichloromethane. A very thin precipitate is formed, which is centrifuged and washed several times with cold dichloromethane, yielding $11.47 \mathrm{mg}$ of green needles (40\%). Elemental analysis calcd (\%) for $\mathrm{C}_{16} \mathrm{H}_{20} \mathrm{NiS}_{6}$ : C 41.47, H 4.35, S 41.51; found C 41.68, H 4.23, S 41.44 .

Synthesis of [Au( $\left.\alpha-(b p t p d t)_{2}\right],(7):$ The neutral complex was obtained by slow diffusion in a test tube. A first layer of $10 \mathrm{mg}(0.01 \mathrm{mmol})$ of 3 in $10 \mathrm{~mL}$ dichloromethane was added to the tube; the interface was formed by $5 \mathrm{~mL}$ acetonitrile; the upper layer contains $2.8 \mathrm{mg}(0.01 \mathrm{mmol})$ iodide in $2 \mathrm{~mL}$ acetonitrile. The product starts precipitating in the interface after 2 hours and is left in the dark overnight. The brown needles are collected by filtration and wash with ether, to yield $3.61 \mathrm{mg}(55 \%)$ of 7 . Elemental analysis calcd (\%) for $\mathrm{C}_{20} \mathrm{H}_{28} \mathrm{AuS}_{6}$ : C 36.52, H 4.29, S 29.24; found C 38.56, H 4.47, S 27.08 .

Synthesis of [Ni( $\left.\alpha-(b p t p d t)_{2}\right],(8)::$ The neutral complex was obtained by slow diffusion in a test tube. A first layer of $8.59 \mathrm{mg}(0.01 \mathrm{mmol})$ of 4 in 10 $\mathrm{mL}$ dichloromethane was added to the tube; the interface was formed by $5 \mathrm{~mL}$ acetonitrile; the upper layer contains $2.54 \mathrm{mg}(0.01 \mathrm{mmol})$ iodide in $2 \mathrm{~mL}$ acetonitrile. The product starts precipitating in the interface after 2 hours and is left in the dark overnight. The green needles are collected by filtration and wash with ether, to yield $4.2 \mathrm{mg}(81 \%)$ of 8 . Elemental analysis calcd (\%) for $\mathrm{C}_{20} \mathrm{H}_{28} \mathrm{NiS}_{6}$ : C 46.24, H 5.43, S 37.03; found C 45.92, H 5.43, S 35.26.

Cyclic voltammetry data were obtained using a BAS C3 Cell Stand. The voltammograms were obtained at room temperature, with scan rate $100 \mathrm{mV} / \mathrm{s}$, Pt wire working and counter electrodes and a $\mathrm{Ag} / \mathrm{AgNO}_{3}$ reference electrode $\left(10^{-3} \mathrm{M}\right)$. The studies were performed in 
dichloromethane solutions of compounds 1-4 $\left(10^{-3} \mathrm{M}\right)$ using TBAPF6 (10 $\left.{ }^{1} \mathrm{M}\right)$ as the supporting. The redox potencials were normalized relatively to the $\mathrm{Fc} / \mathrm{Fc}^{+}$couple, which was used as internal reference.

X-ray Crystallography. Selected single crystals were mounted on a loop with protective oil and X-ray data was collected on a Bruker APEX II CCD detector diffractometer using graphite monochromated MoKa radiation $(\lambda$ $=0.71073 \AA$ ) and operating in a $\varphi$ and $\omega$ scans mode. A semi empirical absorption correction was carried out using SADABS. ${ }^{[24]}$ Data collection, cell refinement and data reduction were done with the SMART and SAINT programs. ${ }^{[25]}$ The structures were solved by direct methods using SIR97 ${ }^{[26]}$ and refined by full-matrix least-squares methods using the program SHELXL97 ${ }^{[27]}$ using the winGX software package. ${ }^{28]}$ Nonhydrogen atoms were refined with anisotropic thermal parameters whereas $\mathrm{H}$-atoms were placed in idealized positions and allowed to refine riding on the parent $\mathrm{C}$ atom. Molecular graphics were prepared using ORTEP 3. ${ }^{[29]}$

Electrical Transport Properties: Electrical conductivity and thermopower were measured in single crystals in the temperature range of $50-320 \mathrm{~K}$, using a measurement cell attached to the cold stage of a closed cycle helium refrigerator. In the first step, the thermopower was measured by using a slow AC (ca. $10^{-2} \mathrm{~Hz}$ ) technique, ${ }^{[30]}$ by attaching two $\varnothing=25 \mu \mathrm{m}$ diameter $99.99 \%$ pure Au wires (Goodfellow), thermally anchored to two quartz blocks, with Pt paint (Demetron 308A) to the extremities of an elongated sample as in a previously described apparatus, ${ }^{[31]}$ controlled by a computer. ${ }^{[32]}$ The oscillating thermal gradient was kept below $1 \mathrm{~K}$ and was measured with a differential $\mathrm{Au}$ 0.05 at. \% Fe vs. chromel thermocouple of the same type. The absolute thermoelectric power of the samples was obtained after correction for the absolute thermopower of the Au leads, by using the data of Huebner. ${ }^{[33]}$

EPR Spectroscopy: The EPR spectra were obtained using a Bruker ELEXYS E500 and Bruker ESP-300 E X band spectrometers equipped with a field-frequency (F/F) lock accessory and a built in NMR Gaussmeter. A rectangular TE102 cavity was used for the measurements. The signal to noise ratio of spectra was increased by accumulation of scans using the F/F lock accessory to guarantee large field reproducibility. Precautions to avoid undesirable spectral distortions and line broadenings, such as those arising from microwave power saturation and magnetic field over modulation, were also taken into account. To control the temperature in the range $4-300 \mathrm{~K}$ an Oxford ESR-900 cryostat was used.

Magnetic Properties: The magnetic susceptibility of the different compounds was measured with a S700X SQUID magnetometer (Cryogenic Ltd) in the temperature range $2-300 \mathrm{~K}$ under applied magnetic fields up to $1 \mathrm{~T}$. All the data were corrected for diamagnetic contributions from the core diamagnetism estimated using Pascal's constants: $X_{D}=-478.9 \times 10^{-6} \mathrm{emu} / \mathrm{mol}(2), X_{D}=-483.2 \times 10^{-6} \mathrm{emu} / \mathrm{mol}(4)$, $X_{D}=-262.0 \times 10^{-6} \mathrm{emu} / \mathrm{mol} \quad(5), \quad X_{D}=-234.0 \times 10^{-6} \mathrm{emu} / \mathrm{mol} \quad(6), X_{D}=-$ $301.2 \times 10^{-6} \mathrm{emu} / \mathrm{mol} \quad(7)$, and $X_{D}=-301.2 \times 10^{-6} \mathrm{emu} / \mathrm{mol} \quad$ (8). AC susceptibility measurements in 7 were taken using a MagLab 2000 system (Oxford Instruments). The temperature dependence of the real and imaginary components of AC susceptibility, $x^{\prime}$ and X", was measured within 1.7 and $50 \mathrm{~K}$ using a 5 Oe oscilating field at frequency $3330 \mathrm{~Hz}$ under zero and 1000 Oe static fields.

\section{Acknowledgements}

This work was supported by FCT (Portugal) through contracts UID/Multi/04349/2013, PTDC/QEQ-SUP/1413/2012 and RECI/QEQ-QIN/0189/2012 and doctoral grants to J.T.C. (SFRH/BD/84628/2012) and R.A.L.S (SFRH/BD/86131/2012).
Keywords: Dithiolene Chemistry • Substituted Thiophene $\bullet$ Gold bisdithiolene Complexes • Nickel bisdithiolene Complexes. • Magnetic Properties •

[1] N. Robertson, L. Cronin, Coord Chem Rev. 2002, 227, 93-127.

[2] R. Kato, Chem Rev 2004,104,5319-5346.

[3] D. Belo, H. Alves, E.B. Lopes, M.T. Duarte, V.Gama, R.T. Henriques M. Almeida, A. Pérez-Benítez, C. Rovira, J. Veciana, Chem. - Eur. J. 2001, 7, 511-519

[4] H. Tanaka, Y. Okano, H. Kobayashi, W. Suzuki, A. Kobayashi, Science 2001, 291, 285-287

[5] H. Tanaka, M. Tokumoto, S. Ishibashi, D. Graf, E.S. Choi, J.S. Brooks S. Yasuzuka, Y. Okano, H. Kobayashi, A. Kobayashi, J. Am. Chem Soc. 2004, 126, 10518-10519.

[6] J. P. M. Nunes, M. J. Figueira, D. Belo, I. C. Santos, B. Ribeiro, E. B. Lopes, R. T. Henriques, C. Rovira, M. Almeida, Chem. - Eur. J. 2007, 13, 9841-9849

[7] N. Tenn, N. Bellec, O. Jeannin, L. Piekara-Sady, P. Auban-Senzier, J. Íñiguez, E.Canadell, D. Lorcy, J. Am. Chem. Soc., 2009, 131, 16961-16974

[8] G. Yzambart, N. Bellec, G. Nasser, O. Jeannin, T. Roisnel, M. Fourmigué, P. Auban-Senzier, J. Íñiguez, E. Canadell, D. Lorcy, J. Am. Chem. Soc. 2012, 134, 17138-17148.

[9] Lorcy, D.; Bellec, N.; Fourmigué, M.; Avarvari, N. Coord. Chem Rev. 2009, 253, 1398-1438.

[10] A.I. S. Neves, I.C. Santos, J.T. Coutinho, L.C. J. Pereira, R.T Henriques, E.B. Lopes, H. Alves, M. Almeida, D. Belo, Eur. J. Inorg. Chem. 2014, 3989-3999.

[11] R. A. L. Silva, B.J.C. Vieira, M. M. Andrade, I. C. Santos, S. Rabaça, D Belo, M. Almeida, Beilstein J. Org. Chem. 2015, 11, 628-637

[12] D. Belo, H. Alves, S. Rabaça, L.C.J. Pereira, M.T. Duarte, V. Gama R.T. Henriques, M. Almeida, E. Ribera, C. Rovira, J. Veciana, Eur. J. Inorg. Chem. 2001, 12, 3127-3133.

[13] R.R. Gagne, C.A. Koval, G.C. Lisensky, Inorg Chem 1980, 19, 2854 2855.

[14] T. Higashino, O. Jeannin, T. Kawamoto, D. Lorcy, T. Mori, M Fourmigué, Inorg. Chem. 2015, 54, 9908-9913.

[15] D.G. Branzea, F. Pop, P. Auban-Senzier, R. Clérac, P. Alemany, E. Canadell, N. Avarvari, J. Am. Chem. Soc. 2016, 138, 6838-6851.

[16] D. G. Branzea, F. Pop, P. Auban-Senzier, R. Clerac, P. Alemany, E. Cannadell, N. Avarvari, J. Am. Chem. Soc., 2016, 138, 6838-6851

[17] Ren, W. Liang, M.-H. Whangbo, Crystal and Electronic Structure Analysis Using CAESAR 1998

[18] R. J. Hoffmann, Chem. Phys. 1963, 39, 1397-1412;

[19] M.-H. Whangbo, R. J. Hoffmann, J. Am. Chem. Soc. 1978, 100, 60936098.

[20] E. Canadell, I.E.-I. Rachidi, S. Ravy, J. P. Pouget, L. Brossard, J. P Legros, J. Phys. France 1989, 50, 2967-2981.

[21] J.C. Bonner, M.E. Fisher; Physical Rev. A 1964, 135, A640-A657.

[22] H. Alves, D. Sima, I. C. Santos, V. Gama, R. T. Henriques, H. Novais, M. Almeida, Eur. J. Inorg. Chem. 2004, 1318-1329.

[23] A. C. Cerdeira, M. L. Afonso, I. C. Santos, L. C.J. Pereira, J. T. Coutinho, S. Rabaça, D. Simão, R.T. Henriques, M. Almeida, Polyhedron 2012, 44 ,228-237.

[24] G.M. Sheldrick, SADABS, Bruker AXS Inc., Madison, Wisconsin, USA 2004

[25] Bruker. SMART and SAINT .Bruker AXS Inc., Madison, Wisconsin USA, 2004

[26] A. Altomare, M.C. Burla, M. Camalli, G. Cascarano, G. Giacovazzo, A Guagliardi, A.G.G. Moliterni, G. Polidori, R. Spagna, J. Appl. Cryst. 1999, 32, 115-119

[27] G.M. Sheldrick, SHELXL97, Program for Crystal Structure Refinement, University of Göttingen, Germany, 1997.

[28] L.J. Farrugia, J. Appl. Cryst. 1999, 32, 837-838.

[29] L.J. Farrugia, J. Appl. Cryst. 1997, 30, 565.

[30] P.M. Chaikin, J.F. Kwak, Rev. Sci. Instrum. 1975, 46, 218-220.

[31] M. Almeida, S. Oostra, L. Alcácer, Phys. Rev. B 1984, 30, 2839-2844.

[32] E.B. Lopes, INETI-Sacavém, internal report, Portugal 1991.

[33] R.P. Huebner, Phys. Rev. A 1964, 135, A1281-A1921. 
1 N. Robertson, L. Cronin, Coord Chem Rev. 2002, 227, 93-127.

2 R. Kato, Chem Rev 2004,104,5319-5346.

3 D. Belo, H. Alves, E.B. Lopes, M.T. Duarte, V.Gama, R.T. Henriques, M. Almeida, A. Pérez-Benítez, C. Rovira, J. Veciana, Chem. - Eur. J. 2001, 7, 511-519.

4 H. Tanaka, Y. Okano, H. Kobayashi, W. Suzuki, A. Kobayashi, Science 2001, 291, 285-287

5 H. Tanaka, M. Tokumoto, S. Ishibashi, D. Graf, E.S. Choi, J.S. Brooks, S. Yasuzuka, Y. Okano, H. Kobayashi, A. Kobayashi, J. Am. Chem. Soc. 2004, 126, 10518-10519.

6 J. P. M. Nunes, M. J. Figueira, D. Belo, I. C. Santos, B. Ribeiro, E. B. Lopes, R. T. Henriques, C. Rovira, M. Almeida, Chem. - Eur. J. 2007, 13, 9841-9849

7 N. Tenn, N. Bellec, O. Jeannin, L. Piekara-Sady, P. Auban-Senzier, J. íñiguez, E.Canadell, D. Lorcy, J. Am. Chem. Soc., 2009, 131, 16961-16974.

8 G. Yzambart, N. Bellec, G. Nasser, O. Jeannin, T. Roisnel, M. Fourmigué, P. Auban-Senzier, J. Íñiguez, E. Canadell, D. Lorcy, J. Am. Chem. Soc. 2012, 134, $17138-17148$.

9 Lorcy, D.; Bellec, N.; Fourmigué, M.; Avarvari, N. Coord. Chem Rev. 2009, 253, 1398-1438.

10 A.I. S. Neves, I.C. Santos, J.T. Coutinho, L.C. J. Pereira, R.T. Henriques, E.B. Lopes, H. Alves, M. Almeida, D. Belo, Eur. J. Inorg. Chem. 2014, $3989-3999$.

11 R. A. L. Silva, B.J.C. Vieira, M. M. Andrade, I. C. Santos, S. Rabaça, D. Belo, M. Almeida, Beilstein J. Org. Chem. 2015, 11, 628-637

12 D. Belo, H. Alves, S. Rabaça, L.C.J. Pereira, M.T. Duarte, V. Gama, R.T. Henriques, M. Almeida, E. Ribera, C. Rovira, J. Veciana, Eur. J. Inorg. Chem. 2001,

$12,3127-3133$

13 R.R. Gagne, C.A. Koval, G.C. Lisensky, Inorg Chem 1980, 19, 2854-2855.

14 T. Higashino, O. Jeannin, T. Kawamoto, D. Lorcy, T. Mori, M. Fourmigué, Inorg. Chem. 2015, 54, 9908-9913.

15 D.G. Branzea, F. Pop, P. Auban-Senzier, R. Clérac, P. Alemany, E. Canadell, N. Avarvari, J. Am. Chem. Soc. $2016,138,6838-6851$.

16 D. G. Branzea, F. Pop, P. Auban-Senzier, R. Clerac, P. Alemany, E. Cannadell, N. Avarvari, JACS DOI 10.1021/jcs.6b03342.

17 J. Ren, W. Liang, M.-H. Whangbo, Crystal and Electronic Structure Analysis Using CAESAR 1998.

18 R. J. Hoffmann, Chem. Phys. 1963, 39, 1397-1412; b)

19 M.-H. Whangbo, R. J. Hoffmann, J. Am. Chem. Soc. 1978, 100, 6093-6098.

20 E. Canadell, I.E.-I. Rachidi, S. Ravy, J. P. Pouget, L. Brossard, J. P. Legros, J. Phys. France 1989, 50, $2967-2981$.

21 J.C. Bonner, M.E. Fisher; Physical Rev. A 1964, 135, A640-A657.

22H. Alves, D. Sima, I. C. Santos,V. Gama, R. T. Henriques, H. Novais, M. Almeida, Eur. J. Inorg. Chem. 2004, 1318-1329.

23 A. C. Cerdeira, M. L. Afonso, I. C. Santos, L. C.J. Pereira, J. T. Coutinho, S. Rabaça, D. Simão, R.T. Henriques, M. Almeida, Polyhedron 2012,44 ,228-237.

24 Sheldrick, G. M. SADABS, Bruker AXS Inc., Madison, Wisconsin, USA, 2004.

25 Bruker. SMART and SAINT .Bruker AXS Inc., Madison, Wisconsin, USA, 2004

26 Altomare, A.; Burla, M. C.; Camalli, M.; Cascarano, G.; Giacovazzo, G.; Guagliardi, A.; Moliterni, A. G. G.; Polidori, G.; Spagna, R. J. Appl. Cryst. 1999, 32, 115-119.

27 Sheldrick, G. M. SHELXL97, Program for Crystal Structure Refinement, University of Göttingen, Germany, 1997.

28 Farrugia, L. J. J. Appl. Cryst. 1999, 32, 837-838.

29 Farrugia, L. J. J. Appl. Cryst. 1997, 30, 565.

30 Chaikin, P. M.; Kwak, J. F. Rev. Sci. Instrum. 1975, 46, 218-220.

31 Almeida, M.; Oostra, S.; Alcácer, L. Phys. Rev. B 1984, 30, 2839-2844.

32 Lopes, E. B. INETI-Sacavém, internal report, Portugal 1991.

33 Huebner, R. P. Phys. Rev. A 1964, 135, A1281-A1921. 